\title{
CONCEPÇÕES DE PROFESSORES DE QUÍMICA SOBRE CIÊNCIA, TECNOLOGIA, SOCIEDADE E SUAS INTER-RELAÇÕES: UM ESTUDO PRELIMINAR PARA O DESENVOLVIMENTO DE ABORDAGENS CTS EM SALA DE AULA
}

\section{Chemistry teachers' conceptions about Science, Technology, Society and relationships among them: a preliminar study to develop a CTS approach in classroom}

\author{
Ruth do Nascimento Firme ${ }^{1}$ \\ Edenia Maria Ribeiro do Amaral ${ }^{2}$
}

Resumo: O presente estudo teve como objetivo investigar como um processo formativo pode contribuir para ressignificar concepções de professores de química sobre Ciência, Tecnologia, Sociedade e de suas interrelações, partindo do pressuposto de que tais concepções são importantes para a implementação de abordagens CTS no ensino de ciências. Participaram da pesquisa três professores de química que atuam em escolas públicas e particulares de PE. A metodologia envolveu atividades como entrevistas individuais e encontros com os professores. A análise das entrevistas revelou concepções dos professores não compatíveis com aquelas esperadas para uma proposta didática na perspectiva CTS, apontando para a necessidade de envolvimento dos professores em uma discussão sobre suas concepções. No sentido de promover essa discussão foram realizados encontros docentes, nos quais foi identificada uma tendência de construção de novos posicionamentos pelos professores, o que revela a importância de um processo formativo para a adoção de abordagens CTS em sala de aula.

Palavras-chave: Concepções docentes. Processo formativo. Abordagens CTS.

\begin{abstract}
This work aimed to investigate how a formative process can contribute to provide new meaning for chemistry teachers' conceptions about Science, Technology, Society and relationships among them, considering these conceptions are important to implement STS approaches for science teaching. Three teachers of chemistry from different public and private schools were involved in this research. Individual interviews were performed with teachers e their conceptions also were analysed from discussions in a workshop. Data analysis revealed some teachers' conceptions seem not be compatible with those required for STS approach, and showed that is crucial to involve teachers in discussions about their conceptions. For this, workshops were performed and discussions pointed out a tendency for construction of new ideas by teachers, highlighting the importance of previous formative process for STS approach in classroom.
\end{abstract}

Keywords: Teachers' conceptions. Formative process. STS approaches.

${ }^{1}$ Licenciatura em Ciências, Habilitação em Química; Mestranda em Ensino das Ciências; professora de Química, Rede Pública de Ensino do Estado de Pernambuco, Secretaria de Educação e Cultura de Pernambuco; Universidade Federal Rural de Pernambuco.

<ruthquimica@yahoo.com.br>

${ }^{2}$ Mestre em Ciência e Tecnologia Nuclear; Doutora em Educação; professora adjunta, Departamento de Química/PPGEC, Universidade Federal Rural de Pernambuco. <edsamaral@uol.com.br>

${ }^{1}$ Rua Professor Francisco Xavier Paes Barreto, 224, apto. 01

Casa Caiada - Olinda, PE

$53.130-240$ 
Firme, R. N.; Amaral, E. M. R.

\section{Introdução}

Neste trabalho foram investigadas concepções de professores de química sobre Ciência-Tecnologia-Sociedade (CTS) e suas inter-relações, partindo do pressuposto de que a implementação de abordagens CTS apresenta estreita relação com essas concepções docentes. Dessa forma, consideramos fundamental, como etapa inicial para o desenvolvimento de abordagens CTS nas salas de aula, fazer um levantamento dessas concepções junto a professores de química e promover um processo de discussão e reflexão sobre aspectos centrais da ciência, tecnologia, e da sociedade na perspectiva de ensino CTS com esses professores.

$\mathrm{Na}$ sociedade contemporânea, aplicações científicas e tecnológicas podem criar possibilidades de desenvolvimento e também gerar problemas sociais e ambientais para o ser humano, sendo assim, um processo educativo em ciências não deveria prescindir da discussão de questões pertinentes ao papel da ciência e da tecnologia na sociedade. Algumas delas seriam: de que forma a ciência e a tecnologia estão presentes na sociedade? Como podemos compreender melhor a relação risco-benefício do desenvolvimento científico e tecnológico? O ensino de Ciências poderá contribuir para formar cidadãos com responsabilidade social diante de problemas do seu tempo? Considerando tais questionamentos, fica ressaltada a potencialidade de contribuição do ensino de Ciências para a formação de cidadãos mais conscientes e críticos frente às aplicações e implicações da ciência e da tecnologia na sociedade. Essa perspectiva se insere nas orientações CTS para o currículo de ciências.

$\mathrm{Na}$ literatura em Educação em Ciências, encontramos diversos trabalhos que apresentam propostas para o ensino com base em uma orientação curricular CTS (CACHAPUZ et al., 2005; VANNUCHI, 2004; MARTINS, 2002; SANTOS e MORTIMER, 2000; SILVA, 2000; ACEVEDO, 1996a). Para Martins (2002), na orientação CTS são tratadas problemáticas socioambientais com base em conceitos da ciência e da tecnologia, e são levantadas questões sobre as implicações sociais do desenvolvimento científico e tecnológico. De uma forma geral, na perspectiva CTS, as propostas de ensino incluem uma abordagem de conceitos científicos articulados a questões tecnológicas e sociais, buscando promover ampla discussão em sala de aula. Tais propostas emergem de um movimento em escala internacional que busca discutir, de forma crítica, as inter-relações entre ciência, tecnologia e sociedade - o Movimento CTS. Em resumo, o Movimento CTS tem como base a constatação de que o desenvolvimento da ciência e da tecnologia não necessariamente apresenta uma relação linear e automática com o bem-estar social. Dessa forma, a ciência e a tecnologia tornaram-se alvos de um olhar mais crítico (AULER e BAZZO, 2001).

As implicações desse movimento no ensino de Ciências podem ser verificadas tomando-se por base a proposta de incorporação de discussões sobre as relações mútuas entre ciência, tecnologia e sociedade no processo de ensino-aprendizagem (SILVA, 2000). Com isso, pretende-se ressaltar que tais discussões sobre o impacto da ciência e da tecnologia sobre diversos setores da sociedade podem implicar uma busca de políticas públicas relativas às aplicações do conhecimento científico e tecnológico na sociedade e suas implicações para o desenvolvimento humano. De uma forma geral, o Movimento CTS propõe, para o ensino de Ciências, uma nova estruturação de conteúdos e procedimentos de ensino. Isso ocorre com base em orientações curriculares que incluam questões tecnológicas e sociais, além dos conceitos científicos e estratégias de ensino que busquem promover uma aprendizagem am- 
pla de conceitos científicos aliada à construção de uma postura cidadã. Diante do desafio proposto, alguns pesquisadores ressaltam a importância de que sejam trabalhadas concepções de professores sobre ciência-tecnologia-sociedade, quando estes estão envolvidos em propostas de ensino na perspectiva CTS (SANTOS e MORTIMER, 2000; ACEVEDO, 1996b).

\section{Os professores e a abordagem CTS}

Em uma perspectiva de ensino CTS, é esperado o desenvolvimento de concepções sobre ciência-tecnologia-sociedade por parte dos professores e alunos, e vários autores têm tentado discutir tais concepções. Com base no trabalho de Mckavanagh e Maher (1982 apud SANTOS e SCHNETZLER, 1997), Santos e Schnetzler (1997) sintetizam concepções desejáveis para uma abordagem de ensino CTS. Segundo os autores, a ciência deve ser considerada como uma busca de conhecimentos socialmente construídos que sofre influência tanto da tecnologia - facilitando ou limitando as pesquisas científicas - como da sociedade, que pode direcionar os rumos dessa ciência. A tecnologia envolve diversos tipos de conhecimentos e sofre influência tanto da pesquisa científica - a produção de novos conhecimentos científicos promove mudanças tecnológicas - como da sociedade, por meio das pressões públicas e a partir das necessidades sociais. A sociedade deve ser vista como uma instituição humana que sofre influência da ciência e da tecnologia, já que o desenvolvimento científico e tecnológico altera o modo de vida das pessoas. Consideramos que essa compreensão de ciência-tecnologia-sociedade e suas inter-relações é de fundamental importância no desenvolvimento de abordagens CTS, e, por esta razão, devemos buscar discuti-las no planejamento didático com os professores e na sala de aula com os alunos.

Atitudes e crenças sobre as relações CTS apresentadas pelo professorado vêm adquirindo cada vez mais importância nas pesquisas sobre este tema. Primeiro, porque o professor não pode ensinar o que não conhece, e, segundo, porque as crenças e atitudes sobre as questões CTS influenciam na prática pedagógica do professor (ACEVEDO, 1996b). Entendemos que o tratamento das concepções docentes acerca da ciência, da tecnologia e da sociedade, bem como das suas inter-relações, tem papel central no processo de implementação de abordagens CTS em sala de aula. É importante que o professor tenha clareza sobre as relações propostas para a ciência-tecnologia-sociedade que estão implicadas nesta abordagem de ensino. No Brasil, ainda são escassas pesquisas sobre concepções de professores acerca de questão CTS. Auler (2002) e Auler e Delizoicov (2006) buscaram identificar compreensões de professores de Ciências sobre interações entre Ciência-Tecnologia-Sociedade (CTS) com a finalidade de respaldar ações no processo de formação inicial e continuada de professores de Ciências. Segundo esses autores, os resultados do estudo parecem apontar para a ausência da compreensão do papel da CT na sociedade pelos professores; e destacam a necessidade de se aprofundarem investigações sobre concepções relativas à suposta neutralidade da CT, uma vez que contradições presentes no pensar dos professores podem dificultar uma compreensão mais crítica sobre as interações entre CTS.

Nesse sentido, reflexões epistemológicas vivenciadas em cursos de formação possibilitariam pôr em questão concepções docentes que potencialmente se constituiriam como obstáculo para a apropriação e incorporação de uma orientação CTS nas práticas pedagógi- 
Firme, R. N.; Amaral, E. M. R.

cas dos professores (CACHAPUZ et al., 2005; MARTINS, 2002). Cachapuz et al. (2005) apontam, dentre outras, algumas dessas concepções: a concepção descontextualizada - ciência e tecnologia como socialmente neutras; a concepção linear e acumulativa - que prevê o avanço da ciência como linear e cumulativo; e a concepção individualista e elitista - que implica uma tendência de ignorar o trabalho coletivo na produção dos conhecimentos científicos. Um outro aspecto relevante a ser considerado é que, muitas vezes, essas concepções podem se converter em obstáculos para uma maior compreensão da atividade científica pelos alunos. A discussão promovida na sala de aula no sentido de construir novas concepções sobre ciência, tecnologia e sociedade poderá contribuir para minimizar visões não adequadas aos desafios para a educação científica contemporânea.

Diante desse quadro, entendemos que um aspecto fundamental para a implementação de novas abordagens de ensino, por exemplo, abordagens CTS, diz respeito também a um processo de formação de professores. Santos e Mortimer (2000) afirmam que não é suficiente inserir mudanças no currículo sem tentar promover, de forma articulada, mudanças nas concepções e na prática pedagógica dos professores. Dessa forma, no processo de implementação de uma abordagem CTS, além de se discutirem as concepções docentes sobre CTS, torna-se relevante evidenciar a concepção de ensino que o professor apresenta, considerando que ela exerce influência na forma como ele atua no processo educativo (ABIB, 1996). Com base nessas considerações, tivemos, neste trabalho, o objetivo de investigar em que medida um processo formativo contribui para (re)significações nas concepções de professores de química acerca da ciência, tecnologia, sociedade e de suas inter-relações. Com isso, consideramos estar promovendo um processo de tomada de consciência do professor sobre as suas próprias concepções, ressaltando a necessidade de mudanças para desenvolver propostas didáticas alternativas àquela usualmente praticada em sala de aula.

\section{Metodologia}

Este estudo é parte de uma pesquisa mais ampla desenvolvida em uma dissertação de mestrado que trata de questões relativas à implementação de uma abordagem CTS em salas de aula de química. Para este estudo preliminar de natureza qualitativa, a investigação envolveu três professores de química do Ensino Médio e consistiu em duas etapas. Inicialmente, foram realizadas entrevistas semi-estruturadas individuais com base em questões abertas, que buscavam captar dos professores as suas concepções acerca de ciência, tecnologia e sociedade e suas percepções sobre as relações ciência-tecnologia, ciência-sociedade e tecnologia-sociedade. As entrevistas tiveram duração de trinta a quarenta minutos cada e foram gravadas em áudio. As gravações foram completamente transcritas e analisadas. Em seguida, os professores foram convidados a participar de um processo formativo, com os objetivos de discutir e refletir sobre aspectos centrais da ciência, tecnologia, sociedade, propostos pela perspectiva de ensino CTS, e de subsidiar a elaboração, pelos professores, de uma intervenção didática com orientação CTS. Nos encontros, foram discutidas concepções consideradas não adequadas para uma abordagem CTS, incluindo aquelas identificadas nas entrevistas com os professores. Os encontros com os professores foram realizados em dois dias, com duração de quatro horas cada, e as atividades realizadas foram gravadas em áudio e vídeo e depois 
transcritas para análise. No primeiro encontro, os professores foram solicitados a expressar suas idéias sobre citações da literatura que versavam sobre aspectos da ciência, tecnologia e sociedade, e, no segundo encontro, foram apresentados e discutidos fundamentos teóricos e metodológicos da orientação curricular CTS.

Para a análise das falas dos professores nas entrevistas e nos encontros docentes, que constituíram o processo formativo, foi considerada a perspectiva de discurso proposta por Bakhtin (1992), sobretudo no que se refere ao fato de as enunciações fazerem parte de uma cadeia de comunicação. Segundo o autor, a enunciação, como unidade de análise, é considerada como produto do ato de fala e é construída como resposta a algo. Em nossa análise, todo enunciado foi considerado como parte de um processo dialógico de comunicação, que tem vínculos com enunciados anteriores e que se constituem como base para enunciados posteriores. Dessa forma, a análise das concepções dos professores foi feita considerando a entrevista como um todo, e não apenas respostas a eventuais questões colocadas pelo pesquisador. Após a análise da transcrição, trechos representativos das entrevistas constituíram blocos ilustrativos de um perfil proposto para cada professor. A análise dos encontros foi feita com base em episódios extraídos dos vídeos e da transcrição, nos quais foram identificados momentos de discussão em que significados relevantes sobre CTS são apresentados pelos professores. Os episódios foram organizados por turnos de fala. Para a análise, foram estabelecidas categorias que denominamos de: significações de ciência, significações de tecnologia, significações de sociedade, e significações das inter-relações ciência-tecnologia, considerando a emergência das concepções dos professores na discussão analisada. Neste trabalho será apresentada a análise feita para quatro episódios extraídos com base em discursos produzidos durante o primeiro encontro, e como ilustração da análise será apresentada na íntegra a transcrição do Episódio 1. Após a análise das falas de cada professor, apresentamos uma análise comparativa entre concepções iniciais (identificadas no momento das entrevistas individuais) e as concepções expressadas nos momentos de discussão do referido encontro.

\section{Resultados e discussão}

Nas entrevistas, as respostas dos professores emergiram quando feitas questões do tipo: O que você pensa sobre ciência? Como você definiria tecnologia? Você poderia apontar algumas relações entre a ciência e a tecnologia? A tecnologia interfere na vida das pessoas de uma sociedade? Em sua opinião, sob quais condições a sociedade teria o poder de tomada de decisão acerca dos avanços científicos e tecnológicos? As respostas foram organizadas em bloco para cada professor, considerando que, no discurso produzido ao longo da entrevista, muitas vezes, é constituída uma cadeia de idéias que se superpõem ou se complementam (BAKHTIN, 1992). Alguns trechos da fala da professora A são apresentados a seguir com o intuito de possibilitar uma melhor compreensão da análise feita. A professora A cursou Química Industrial e Licenciatura em Química, tem vinte anos de magistério, e participou de diversos processos de formação continuada, sendo atualmente professora de uma escola pública de Recife. 
Firme, R. N.; Amaral, E. M. R.

\section{Trechos de respostas da professora $A$}

"[...] a gente tem que ver que a ciência não é isolada não é? Então a ciência seria um conjunto de conhecimentos, não é isso? Onde o indivíduo estaria interagindo de forma não estagnada nem estanque com o mundo". (aspectos relevantes da concepção de ciência)

"A tecnologia seria assim... Vamos supor, à medida que a ciência vai se superando a tecnologia vai se inovando. É porque realmente em termos de conceituar, dizer o que é tecnologia, eu acho, eu não tenho muito assim, essa questão de dizer com palavras, eu acho que a tecnologia é a busca da inovação [...]" (aspectos relevantes da concepção de tecnologia)

"Se a gente for pela etimologia da palavra, sociedade, sociedade a gente reúne o quê? Um grupo de pessoas pode ser, está ligado com a humanidade, com o social, o que envolve um todo, um conjunto. Vamos supor, quando a gente diz assim, ah, preparar o indivíduo para ser um cidadão, para ser um ser social, a sociedade para você participar dela você tem que interagir, você tem que ser ativo, participativo, e para que você possa participar desse social você também vai ter que se desenvolver, não é?" (aspectos relevantes da concepção de sociedade)

"Eu acho que primeiro a ciência tem que desenvolver. Vamos supor, se eu quero fabricar um foguete, eu preciso de uma tecnologia para desenvolver esse foguete. [...] vou me basear em que? No desenvolvimento da ciência. Fazer uma pesquisa. Vai ter que ter um ponto de partida." (aspectos relevantes da concepção sobre as inter-relações ciência-tecnologia)

"Eu acho que a ciência está presente na sociedade, agora a sociedade não consegue ver que ali está inserida a ciência. Não sei se você entendeu o que eu quero dizer, ou seja, eles ainda não despertaram para o olhar que estar em volta dela [...]"

(Em outro momento da entrevista foi questionado se a ciência tem influência sobre a sociedade)

"Depende [...] Porque quando você vê, é quando você diz a sociedade, cada sociedade tem a sua cultura [...] Vamos supor, se eu tiver numa sociedade indígena, será que a ciência vai influir dentro dessa sociedade? Eu acho que depende do tipo de sociedade que você está inserida. Eu não sei se você entendeu, mas eu imagino assim. Você só vê que a ciência vai interferir a partir da hora que você vê o significado, porque qual o significado da ciência para o índio?"

(Foi questionada a influência que a pesquisa científica pode sofrer de fatores externos)

"Com certeza. Eu acho que um dos fatores que a gente vê que pesa muito é a questão econômica. A questão econômica tem falado bem mais alto não é?" (aspectos relevantes da concepção sobre as interrelações ciência-sociedade)

"Eu acho que muda até as condições de vida de cada um. Deixa eu começar a pensar. Quando a gente fala de tecnologia só pensa de máquina, mas a tecnologia está envolvida em tudo. Hoje em dia, tudo precisa de tecnologia. Então vamos supor: eu gosto muito de falar com meus alunos a questão da alimentação. $O$ hábito alimentar. O desenvolvimento tecnológico vive mudando o hábito alimentar da gente."

(Em outro momento da entrevista foi questionada a relação da sociedade com a tecnologia)

"Eu acho que são as necessidades de uma sociedade que fazem com que se busquem novas tecnologias." (aspectos relevantes da concepção sobre as inter-relações tecnologia-sociedade)

Em nossa análise, consideramos que a professora A parece compreender a ciência como um conjunto de conhecimentos que não se constituem de forma isolada nem estagnada, e que esse conjunto de conhecimentos proporciona uma interação dinâmica dos indivíduos com o mundo. Entendemos que essa concepção da professora acerca da ciência corres- 
ponde, de certa forma, à compreensão de uma ciência como produção humana, a qual possibilita a leitura do mundo pelo homem e para o homem. Com relação à compreensão da professora sobre tecnologia, percebemos certa dificuldade de expressão das idéias em palavras, e, na tentativa de elaborar uma definição, ela expressa uma compreensão da tecnologia como busca de inovação, que poderia ser considerada associada ao desenvolvimento de produtos tecnológicos a partir do conhecimento científico. Isso fica mais claro quando a professora se refere aos hábitos alimentares em uma resposta posterior. A sociedade, para a professora A, se caracteriza por um grupo de pessoas que busca participação, identidade cultural e desenvolvimento dentro da mesma. Na definição não aparecem explicitamente, como constituintes dessa sociedade, possíveis grupos que exercem pressão sobre o desenvolvimento científico, citado em resposta posterior.

Quanto às percepções acerca das interações CTS, observamos que, na relação ciência-tecnologia, a professora A entende a ciência como determinante para a tecnologia. Em nenhum momento foi explicitada uma compreensão, por parte da professora, de que a tecnologia pode exercer influência sobre a ciência ao limitar ou possibilitar o desenvolvimento de novas pesquisas científicas. Consideramos que essa visão apresenta a tecnologia como aplicação dos conhecimentos científicos, e essa idéia da tecnologia como subproduto dos conhecimentos científicos pode reforçar uma percepção que supervaloriza a ciência em detrimento da tecnologia. Essa forma de conceber a relação ciência-tecnologia pode ser resultado de pouco esclarecimento acerca das influências mútuas exercidas entre a ciência e a tecnologia. Tal postura, para Cachapuz et al. (2005), poderá promover, no âmbito do ensino das disciplinas científicas, uma concepção descontextualizada sobre a tecnologia.

A relação ciência-sociedade é percebida pela professora A nos dois sentidos: no primeiro, a ciência exerce efeito sobre algumas sociedades se estas possuem uma percepção de que a mesma se faz presente na vida das pessoas; e, no segundo, na sociedade, alguns grupos específicos (econômicos) podem exercer influência no direcionamento de pesquisas científicas. A professora A admite que a ciência não influencie alguns tipos de sociedade, por exemplo, a indígena. Entretanto, ela não expressa idéias que apontem claramente para a possibilidade de que a sociedade, formada por cidadãos comuns, possa exercer influência sobre a ciência. Este fato nos permite salientar que, numa perspectiva de ensino com abordagem CTS, a sociedade é concebida como uma organização social na qual os cidadãos devem intervir em questões sociais relacionadas com os aspectos científicos (SANTOS e SCHNETZLER, 1997).

Finalmente, com relação à interação tecnologia-sociedade, a professora A compreende essa interação tanto por expressar que a tecnologia está presente em todos os âmbitos da sociedade contemporânea, como por entender que os avanços tecnológicos partem das necessidades que a sociedade apresenta. Consideramos que a percepção da professora parece se aproximar de aspectos propostos na abordagem CTS discutidos por Santos e Schnetzler (1997), os quais indicam que a tecnologia influencia na forma de vida de uma sociedade, e que as necessidades dessa sociedade podem promover mudanças tecnológicas.

De um modo geral, consideramos que a professora A expressou uma concepção de ciência mais próxima de uma perspectiva de produção humana, que precede, subsidia e fundamenta os avanços tecnológicos. No entanto, vale ressaltar que a mesma não faz menção sobre uma possibilidade de a tecnologia produzir conhecimentos próprios em contextos específicos (CACHAPUZ et al., 2005). Com relação à concepção de sociedade, ela considera 
que a mesma pode ou não sofrer influência dos conhecimentos científicos, ou seja, grupos sociais que não têm acesso a esses conhecimentos, e também cidadãos comuns, na sua maioria, parecem não ter participação no direcionamento dos rumos da ciência e da tecnologia. A concepção de tecnologia apresentada como uma busca de inovação que parte das necessidades de uma sociedade e que promove mudanças nas condições de vida dessa sociedade faz emergir questões relativas ao pequeno percentual de cidadãos que possuem acesso à tecnologia. Além disso, pode ser questionada a ausência de considerações sobre o setor da sociedade do qual partem as necessidades, as quais prioritariamente determinariam o avanço tecnológico. Tais fatos não são enfatizados nas respostas da professora, mas poderiam ser discutidos em sala de aula. Em resumo, dentre outros aspectos, a influência do cidadão comum no desenvolvimento científico e tecnológico e a abrangência social desse desenvolvimento podem ser discutidas com essa professora no planejamento de uma abordagem CTS para a sua sala de aula. Nesse sentido, também pode ser evidenciado que a formação do aluno na perspectiva da cidadania lhe reveste de certo poder de transformação do seu contexto social.

Análise semelhante foi feita com relação ao professor $\mathrm{B}$ e à professora $\mathrm{C}$, no entanto, o quadro das respostas será omitido por limitações de espaço. O professor B cursou Licenciatura em Química, tem sete anos de magistério, leciona em escolas públicas e particulares de Recife, e estava participando pela primeira vez de um processo de formação continuada (curso de especialização).

Para o professor B, a ciência se apresenta como um conjunto de informações que busca responder às questões relevantes da vida do homem em diferentes períodos. Nesse sentido, entendemos que o professor parece expressar uma concepção na qual cabe à ciência uma produção intelectual capaz de dar respostas aos questionamentos humanos. Entretanto, não percebemos, na fala do professor, que tais questionamentos podem incluir uma dimensão social, ou seja, a busca de conhecimentos levando em consideração questões sociais, aspecto este importante em uma abordagem CTS (SANTOS e SCHNETZLER, 1997). Além disso, não fica explícito que é o próprio homem quem produz tais conhecimentos científicos. Ao tentar definir tecnologia e sociedade, o professor apresentou respostas sucintas, que foram mais desenvolvidas quando buscou explicar interações entre elas. Tal como a professora $\mathrm{A}$, a concepção de tecnologia revelada pelo professor B está associada a uma dimensão da técnica instrumental. Entendemos que essa visão sugere uma tecnologia unicamente de caráter operacional, não tendo sido explicitada qualquer relação com a produção de conhecimento. Alguma menção nesse sentido aparece de forma tímida em resposta posterior. O professor expressou uma compreensão geral sobre a sociedade, como qualquer agrupamento de pessoas que se organiza em termos de regras e leis.

Quanto às percepções acerca das interações CTS, verificamos que o professor B expressou uma compreensão de que ciência e tecnologia andam juntas, mas entende que o conhecimento científico precede o desenvolvimento tecnológico. Tal entendimento pode contribuir involuntariamente para difundir, no ensino das disciplinas científicas, uma concepção elitista e individualista de ciência que considera a tecnologia numa perspectiva puramente operativista (CACHAPUZ et al., 2005). No entanto, o professor expressou um entendimento de que a tecnologia amplia os avanços da pesquisa científica. Com relação à interação entre ciência e sociedade, o professor B expressou a concepção de que a ciência promove efeitos sobre a sociedade no que se refere à sua aplicabilidade. E apresentou a compreensão de que 
grupos externos à comunidade científica interferem nos rumos da ciência, sendo que, mais uma vez, a participação do cidadão comum não foi evidenciada. Entretanto, o professor ressaltou que a possibilidade de uma intervenção mais ampla da sociedade nas questões relativas à ciência estaria relacionada com informações significantes oferecidas à população, ou seja, por meio do processo educativo. Nesse sentido, é ressaltada a importância da educação para o incentivo à participação social nas tomadas de decisão relativas ao desenvolvimento científico. Em outras palavras, o professor parece entender que os alunos precisam ter consciência do poder de influência que têm como cidadãos de uma sociedade (SANTOS e SCHNETZLER, 1997). Com relação à interação entre tecnologia e sociedade, o professor expressa claramente que a tecnologia influencia a forma de vida das pessoas, entretanto, compreende que a sociedade só terá condições de participar na tomada de decisões acerca de questões tecnológicas se forem estabelecidas leis que possibilitem tal participação. Vale salientar que o professor evidencia os processos exclusivos promovidos por um desenvolvimento tecnológico restrito a certas camadas sociais. Diante disso, percebemos que o mesmo compreende a relação tecnologia-sociedade considerando que a influência tecnológica numa sociedade tem duas faces: a inclusão e a exclusão social.

De modo geral, o professor B apresentou uma concepção de ciência como busca de respostas para as questões atuais, reconhecendo que ela exerce influência sobre a sociedade por meio da aplicação dos conhecimentos científicos, e tem primazia sobre a tecnologia. A tecnologia, segundo o professor, pode contribuir para ampliar o desenvolvimento científico e interfere na vida de alguns grupos sociais, não estando disponível de forma ampla para todos os cidadãos. A sociedade é um grupo de pessoas que sofre influência do desenvolvimento científico e tecnológico, porém ainda não apresenta uma participação ampla e efetiva na tomada de decisão, considerando o contexto das questões científicas e tecnológicas. Com base nas respostas do professor $\mathrm{B}$, quanto ao planejamento didático, um dos pontos a serem enfatizados seria a idéia de ciência como uma construção humana, e como tal, suscetível às influências da sociedade na proposição de seus modelos explicativos e teorias. E a tecnologia, como produtora de conhecimento próprio, não necessariamente como aplicação dos conhecimentos científicos, está presente de alguma forma na vida de todo o cidadão.

A professora C cursou Licenciatura Plena em Ciências com habilitação em Química, tem 17 anos de prática docente, e participou de diversos programas de formação continuada, sendo atualmente professora de uma escola pública do Recife. A professora $C$ revela uma concepção de ciência como um conjunto de conhecimentos que estaria associado ao contexto sociohistórico no qual é produzido. Da análise de suas respostas, percebemos duas características da ciência: a aplicabilidade do conhecimento científico e a transformação desse conhecimento ao longo dos anos. Entendemos que a professora expressa uma concepção não dogmática de ciência, ou seja, a mesma não se constitui de verdades e certezas absolutas. Entretanto, consideramos importante ressaltar que não há menção sobre como a professora concebe a transformação dos conhecimentos científicos ao longo da história. Nesse sentido, seria importante que não se configurasse uma imagem de ciência como produto do acúmulo linear do conhecimento (CACHAPUZ et al., 2005), pois tal visão pode desfavorecer uma postura crítica e ativa no processo de desenvolvimento científico da sociedade, uma vez que não seriam evidenciadas possíveis rupturas e redirecionamentos em tal processo. Nessa perspectiva, a idéia de ciência como construção humana parece ficar prejudicada. A professora $\mathrm{C}$ 
apresenta uma postura predominantemente otimista frente ao que é produzido pela ciência, sendo citadas aplicações em benefício do homem, sem mencionar possíveis prejuízos que podem advir do mau uso do conhecimento científico. Isso pode resultar na idéia de que é desnecessária a intervenção da sociedade, o que fica mais claro em respostas posteriores. A professora concebe a tecnologia como a aplicação do conhecimento científico com vistas ao bem comum, e expressa idéias que associam o desenvolvimento tecnológico ao atendimento das necessidades sociais (SANTOS e SCHNETZLER, 1997). Parece compreender também que, em situações específicas, a tecnologia pode gerar conhecimentos próprios (CACHAPUZ et al., 2005). Quanto à sociedade, a professora $\mathrm{C}$ a compreende como um todo formado por estratos específicos, que desempenham diferentes funções. Essa percepção sobre as divisões sociais principalmente marcadas pelas atividades exercidas pelos cidadãos parece dificultar a visão mais ampla de uma sociedade formada por cidadãos comuns que podem exercer influência e tomar decisões em problemas sociais concretos.

Com relação às interações CTS, a professora C apresenta uma compreensão da interdependência entre a ciência e a tecnologia, pois expressa idéias de que a tecnologia advém da ciência e os instrumentos tecnológicos influenciam de forma positiva no avanço da pesquisa científica. Mais uma vez, prevalece uma visão otimista do progresso científico e tecnológico. A relação ciência-sociedade é concebida, pela professora $\mathrm{C}$, com base na aplicabilidade dos conhecimentos científicos na sociedade e na percepção de que fatores externos influenciam o desenvolvimento da pesquisa científica. Porém, a professora não admite a possibilidade de a sociedade interferir no rumo das pesquisas científicas. No entanto, percebemos que essa postura pode estar focada na dificuldade de se construir tal participação, considerando que seria impossível ("nunca") chegar a consensos, e não como uma idéia de que a sociedade passa ao largo da produção científica. Com base em tal posicionamento, podemos apontar para a importância de se discutir, com a professora C, que tipo de participação se pretende construir com uma formação cidadã, valendo-se de uma abordagem CTS em sala de aula. Com relação à interação entre tecnologia e sociedade, a professora percebe essa interação quando considera que a sociedade usufrui da tecnologia e que o consumo de produtos pela sociedade estimula determinados avanços tecnológicos. Mais uma vez, isto nos leva a considerar que a concepção da professora acerca da participação da sociedade no desenvolvimento científico e tecnológico no qual está imersa resume-se a uma perspectiva mais pragmática e utilitária dos produtos gerados pela tecnologia.

De um modo geral, a professora $C$ parece demonstrar uma concepção otimista e, até certo ponto, ingênua de ciência, como um conjunto de conhecimentos que podem ser aplicados para a produção de melhores condições de vida para a sociedade. Apresentou concepções nas quais a ciência e a tecnologia são consideradas interdependentes na produção de conhecimentos, e que interferem na sociedade pela necessidade do consumo de produtos e estímulo a novas pesquisas. Por outro lado, a professora não concebe a possibilidade da participação social na tomada de decisões a respeito das questões sobre a ciência. O perfil da professora $\mathrm{C}$ aponta algumas possibilidades de discussão e, dentre elas, destacamos: aspectos do desenvolvimento científico e tecnológico que prejudicam a qualidade da vida na Terra (degradação do ambiente, promoção de guerras etc.); e a necessidade de que a sociedade, pensada de forma mais ampla (todos os seus segmentos), exerça um controle sobre a produ- 
ção científica e tecnológica, no sentido de garantir o respeito aos direitos mais essenciais do ser humano e a preservação/conservação da natureza.

Em síntese, as concepções apresentadas pelos professores apontam para a necessidade de discussão sobre o processo de elaboração de propostas de abordagens CTS, considerando aspectos tais como: o fortalecimento da idéia de ciência como uma construção humana, suscetível às influências da sociedade e como uma das formas de interpretação do mundo; a construção de uma visão menos instrumental e mais influente da tecnologia no que se refere à produção do conhecimento científico, buscando evidenciar as formas como caminham juntas ciência e tecnologia; e, finalmente, uma visão de sociedade não somente consumidora, mas intrinsecamente participante na produção da ciência e tecnologia, estando o seu poder de ação tanto no âmbito dos grupos de maior influência social como ao alcance do cidadão comum organizado e consciente. Com relação a este último, a formação cidadã seria um caminho de conscientização de alunos e professores sobre a força social que possuem. Essas sugestões de discussão que emergiram da análise das respostas dos professores nas entrevistas foram incluídas nos encontros com os professores para promover uma reflexão e subsidiar o planejamento de uma abordagem CTS nas suas salas de aula. A seguir será apresentada a análise das discussões que ocorreram no primeiro encontro docente, que está organizada em categorias de análise, conforme mencionado anteriormente na Metodologia.

\section{Análise do primeiro encontro docente}

No primeiro dia de encontro com os professores, as atividades foram direcionadas para o tratamento dos indicadores que emergiram da síntese da análise das entrevistas individuais. Tais indicadores referiram-se ao fortalecimento da idéia de ciência como uma construção humana; à construção de uma visão menos instrumental e mais influente da tecnologia; e à visão de sociedade não somente consumidora, mas participante. De um modo geral, neste primeiro momento, os professores foram solicitados a se posicionar individualmente quanto às percepções apresentadas em citações extraídas da literatura. Os professores escreviam se estavam ou não de acordo com a citação e o porquê, e em seguida, socializavam o seu posicionamento com o grande grupo.

Uma primeira análise da discussão foi feita com relação ao momento em que cada professor foi solicitado a se posicionar com base na leitura da seguinte citação: "Como empreendimento humano, a Ciência é falível; ela pode degenerar ou pode responder às supremas aspirações dos homens. Como parte da sociedade, a Ciência também está aberta a influências externas; como qualquer atividade social, pode ser bem ou mal usada" (KNELLER, 1980, p. 9). O episódio 1 é representativo do momento no qual os professores expressam concepções sobre a ciência com base na citação. Ao analisarmos as falas dos professores, percebemos que os mesmos apresentam concepções de ciência como um conjunto de idéias que não é absoluto e que pode ter aplicações benéficas ou maléficas, apesar de haver alguma relutância com este tipo de postura (turnos 3, 5 e 7). As expressões docentes parecem revelar uma concepção de ciência gerada num meio social (FREIRE-MAIA, 2000), e, neste caso, sofre influência de fatores que constituem a cultura da qual faz parte, tendo a mesma um poder relativo (turno 6). 
Firme, R. N.; Amaral, E. M. R.

Episódio 1. Expressões dos professores que representam Significações de ciência.

\begin{tabular}{|c|c|}
\hline 1. Professora $A$ : & $\begin{array}{l}\text { "A ciência hoje busca investigar e explicar situações envolvendo a sociedade e a } \\
\text { tecnologia. Portanto deve estar aberta para ajudar a suprir as necessidades de } \\
\text { uma sociedade de forma consciente. Isto é como eu vejo a ciência hoje, antes eu } \\
\text { via a ciência como se ela estivesse numa redoma de vidro e que as coisas só } \\
\text { poderiam ser explicadas a partir dela. [...] Mas hoje, ela está saindo dessa redoma } \\
\text { e está buscando, através da sociedade, essa explicação." }\end{array}$ \\
\hline 2. Professor $\mathbf{B}$ : & "Você concorda ou não concorda com o texto?" \\
\hline 3. Professora $A$ : & $\begin{array}{l}\text { "O que eu quis dizer foi isso. Que a ciência é falível, é, não é? Por isso que eu } \\
\text { disse que busca investigar, [...]. Eu concordo parcialmente com o texto." }\end{array}$ \\
\hline 4. Professor B: & $\begin{array}{l}\text { "Eu concordo na íntegra. Porque eu acredito numa ciência como instrumento de } \\
\text { desenvolvimento humano, e como tal, fica a critério de quem vai fazer uso de suas } \\
\text { atribuições. Vai ser utilizada para o bem ou para o mal." }\end{array}$ \\
\hline 5. Professora C: & $\begin{array}{l}\text { "Eu concordo também. Realmente, a ciência pode sofrer influências externas } \\
\text { profundas, porque pode ser usada para o bem ou para o mal. São tantos os } \\
\text { exemplos que o desenvolvimento da ciência foi muito mal usado como } \\
\text { empreendimento humano, tais como: os explosivos, aviação voltados para guerra, } \\
\text { agrotóxicos etc. Contudo trouxe tantos outros benefícios como remédios, } \\
\text { cosméticos, vacinas etc. Quem faz uso para o bem ou para o mal da ciência é o } \\
\text { homem. A ciência em si não faz malefícios." }\end{array}$ \\
\hline 6. Professor B: & "Ela é um instrumento." \\
\hline 7. Professora C: & "Exatamente. O homem é que não tem muito bom senso." \\
\hline
\end{tabular}

De um modo geral, observamos que, no discurso da professora A, permaneceu a concepção de ciência com caráter social, revelada na entrevista. No entanto, apesar do reconhecimento de uma mudança de postura (turno 1), a professora parece ainda relutar para se posicionar sobre a falibilidade da ciência (turno 3). Na fala do professor B, percebemos novos posicionamentos relativos à concepção anteriormente colocada para a ciência (turno 4), uma vez que esse professor mostrou indícios da percepção do envolvimento da ciência com as necessidades sociais da humanidade. Com relação à professora $\mathrm{C}$, percebemos novos posicionamentos em sua concepção de ciência, uma vez que, na entrevista, apresentou a ciência como um conjunto de conhecimentos com aplicabilidade prática para melhorar a vida das pessoas. E agora, no discurso produzido coletivamente com base em uma citação, manifestou uma concepção de ciência mais aberta às influências externas que podem acarretar problemas para as pessoas (turnos 5 e 7 ).

Entendemos que as significações de ciência colocadas pelos professores naquele momento parecem caminhar em uma direção que se torna mais próxima daquela considerada como adequada para a implementação de uma abordagem CTS em suas salas de aulas. No entanto, um ponto importante a ser colocado diz respeito ao fato de haver uma tendência do grupo a concordar com o que está dito no texto, provavelmente por reconhecer a competência do autor no assunto. Por esta razão, não seria possível interpretar os novos posicionamentos como uma mudança de concepção, mas como o resultado de uma reflexão feita naquele momento e que pode vir a promover mudanças na visão de ciência. 
As análises dos episódios 2, 3 e 4 foram realizadas com o mesmo procedimento analítico do episódio 1. Como os episódios não foram apresentados na íntegra, algumas citações de falas, extraídas dos episódios, serão colocadas como ilustração. No entanto, vale ressaltar que, no processo de análise, as citações foram consideradas com base em uma transcrição das falas na íntegra. A segunda análise da discussão (episódio 2) foi feita com relação ao momento em que cada professor foi solicitado a se posicionar valendo-se da leitura da seguinte citação: "Uma tecnologia, portanto, não é somente um conjunto de elementos materiais, mas também um sistema social. Certos aparelhos, aliás, podem se tornar absolutamente inúteis nos países em desenvolvimento que não possuem as infra-estruturas sociais e culturais que lhes implicam" (FOUREZ, 1995, p. 218). O episódio 2 representa o momento em que os professores expressam concepções sobre a tecnologia com base na citação. Da análise das idéias apresentadas pelos professores, percebemos que o professor B parece não ter compreendido bem a relação entre tecnologia e sociedade proposta pelo autor na frase, e isso pode ser percebido na sua fala que busca traduzir as palavras expressas pelo autor. As professoras A e C parecem ter compreendido e concordado com a afirmação posta: a tecnologia é um processo social uma vez que pode ser considerada como um empreendimento humano que consiste em satisfazer necessidades humanas. Ou seja, a tecnologia deve surgir das demandas que a sociedade tem, e, nesse sentido, se torna dependente das condições em que esta sociedade vive. Nessa perspectiva, parece não haver a percepção do fato de que a tecnologia, independentemente de uma demanda social explícita, pode influenciar nas formas de vida e organização social.

No confronto com as concepções reveladas nas entrevistas individuais, observamos que, na fala da professora A: "Eu posso importar a tecnologia, mas que não vai me atender por falta de preparo. Cada sociedade deve desenvolver a sua tecnologia de acordo com as suas necessidades. Para se chegar a isso épreciso não só ter, mas também ser", permaneceu a idéia de que a tecnologia parte das necessidades de uma sociedade. O professor B colocou: "Para mim, a tecnologia e suas aplicações devem nortear características da sociedade inserida. Baseado neste contexto, quando você diz que 'a tecnologia não é somente um conjunto de elementos materiais'. Perfeito. [...] acredito que a tecnologia não é somente um conjunto de elementos materiais, mas é um sistema social. [...]. Agora, 'certos aparelhos podem se tornar absolutamente inuiteis nos paises em desenvolvimento que não possuem as infra-estruturas sociais e culturais que lhes implicam', vai depender, vai depender das suas estruturas e das suas tecnologias e a sua aplicação, pois elas devem caminhar com as características daquela sociedade em que ela está inserida. Por exemplo, um país muito desenvolvido tecnologicamente, a maioria do produto tecnológico gerado vai acarretar num bem estar da grande maioria da população". Com base em sua fala, percebemos um posicionamento diferente em seu discurso, de uma concepção de tecnologia numa perspectiva mais instrumental, ele tenta se apropriar de uma concepção de tecnologia como sistema social e, dessa forma, também cultural. A professora C expressou: "Eu concordo certo. Quando li esse texto eu pensei na Africa e pensei no Brasil. Veja bem, concordo com o texto. Dependendo do desenvolvimento da sociedade, a tecnologia pode ser útil e necessária, ou ser completamente desnecessária. É o contexto da sociedade que vai direcionar". Ela também nos revelou um novo posicionamento acerca da concepção de tecnologia ao situar a tecnologia no contexto das necessidades de uma sociedade, movendo-se da percepção da tecnologia como aplicação do conhecimento científico para uma concepção de tecnologia que advém também de uma dimensão social. Os professores parecem ter percebido dimensões da tecnologia sobre as quais antes não haviam refletido. Dessa forma, os encontros parecem ter oportunizado uma ampliação da perspectiva colocada na entrevista. 
Firme, R. N.; Amaral, E. M. R.

O terceiro episódio (episódio 3) analisado se refere ao momento em que cada professor foi solicitado a se posicionar com base na leitura da seguinte citação:

Em definitivo, a participação dos cidadãos na tomada de decisão é hoje um fato positivo, uma garantia de aplicação do princípio de precaução, que se apóia numa crescente sensibilidade social face às implicações do desenvolvimento tecno-científico que pode comportar riscos para as pessoas ou para o ambiente. (CACHAPUZ et al., 2005, p. 28)

O episódio 3 é representativo do momento em que os professores expressam concepções de sociedade valendo-se da citação. Ao analisarmos as falas dos professores, o professor B parece não acreditar na possibilidade de participação cidadã na tomada de decisão acerca das questões científicas e tecnológicas, e justifica a sua posição considerando questões políticas. Isto pode ser percebido com base na fala do professor B: "Talvez porque tu tenhas analisado o texto de forma bem geral. Eu fui muito restrito na minha análise, eu pensei em termos de Brasil. Por isso que não concordo. Pois não percebo no Brasil que as tomadas de decisão são dos cidadãos. Muito pelo contrário, hoje o nosso desenvolvimento tecnológico vem atendendo a uma minoria a qual toma as decisões em nossopais".

A falta de credibilidade do professor B parece ser fundada em dificuldades reais que crê existirem para que haja uma participação cidadã no nosso país e, dessa forma, parece não conseguir vislumbrar uma possível construção dessa postura para professores e alunos, dentro e fora da escola. Entretanto, observamos posições diferentes nas professoras A e C, ressaltando que a professora $\mathrm{C}$ parece estar confusa com relação à citação e acaba concordando majoritariamente com a argumentação feita pela professora A. Essas professoras expressam a necessidade da participação dos cidadãos nas tomadas de decisão: "Agora eu vou dizer por que eu concordo com a citação. É importante a formação do ser crítico e participativo, buscando soluções que possam ajudar na aplicabilidade, minimizando danos atrelados ao desenvolvimento tecnológico" (professora A); "Foi isso que eu pensei. Você joga o produto no mercado, se esse produto trouxer algum mal para a sociedade, ela vai excluir esse produto" (professora C). Elas apontam ações que podem ser realizadas no contexto escolar para preparar o cidadão crítico e participativo que busque soluções que minimizem os impactos socioambientais produzidos pela tecnologia, e para socializar o desenvolvimento técnico-científico.

$\mathrm{Na}$ busca de relações entre as concepções dos professores identificadas nas entrevistas e aquelas expressadas nos momentos de discussão sobre a percepção de sociedade, observamos que a professora A, quando expressou: "Por exemplo: eu não vou comprar um detergente não biodegradável porque eu sei que vai acelerar a poluição, não é?’, pareceu apresentar um novo posicionamento quanto à sua concepção de sociedade ao situá-la num contexto contemporâneo que exige dos cidadãos participação e consciência crítica frente aos danos provocados pelo desenvolvimento científico e tecnológico. Com relação ao professor B, quando fez a colocação citada anteriormente, identificamos, em suas falas, indícios de permanência da concepção de sociedade participativa vinculada às condições estabelecidas por uma minoria (talvez política e econômica). E o discurso da professora C: "A socialização do desenvolvimento técnico-científico traz. melhorias de vida para a sociedade participante", pareceu apontar para um novo posicionamento na 
medida em que passa a conceber a sociedade numa perspectiva mais ampla, não caracterizada por grupos ou esferas sociais isolados, que necessita da socialização dos conhecimentos científicos e tecnológicos na concretização de uma participação social e democrática mais efetiva.

Com relação às inter-relações CTS, direcionamos nosso foco de análise para as interrelações entre a ciência e a tecnologia, uma vez que algumas pesquisas (VALDÉS et al., 2002; ACEVEDO, 1995) apontam concepções docentes não adequadas acerca de tal relação. A análise da discussão do episódio 4 foi feita com relação ao momento em que os professores fizeram a leitura de um texto que tratava da construção da luneta por Galileu (VANNUCHI, 2004). Com o objetivo de colocar em discussão a relação ciência-tecnologia, questionou-se, com os professores, se o problema enfrentado por Galileu na construção da luneta foi de ordem científica ou tecnológica. O episódio 4 ilustra o momento em que os professores expressam concepções da inter-relação ciência-tecnologia.

Nas expressões dos professores: "Ele desenvolveu uma tecnologia, mas precisava ser ampliada, ser fundamentada" (professora A); "Até para responder essa necessidade dele de fazer uma lente mais potente" (professor B), percebemos a idéia de uma difusa inter-relação ciência-tecnologia pelo fato de esses professores não desvincularem, na produção do objeto "luneta", o conhecimento científico do conhecimento tecnológico. Em suas percepções, estes conhecimentos estão bem entrelaçados, de forma que a questão da ordem em alguns momentos não se configurou relevante. Quando o professor B colocou: "Isso que você falou não é verdade absoluta. Nem sempre a tecnologia precisa de uma fundamentação teórica por trás", ou: "O que eu percebi é que a ordem não importa. O que importa é que a ciência e a tecnologia caminhem juntas nesse contexto", parece-nos que tais percepções levam a uma compreensão da ciência e tecnologia como domínios distintos, mas que se influenciam mutuamente na consolidação dos saberes. Por outro lado, quando a professora C expressou: "E foi isso que ele fer. Se soubesse o problema cientificamente ele não teria usado a lente plana. Mas ele usou e não fez efeito. Aí ele passou para a côncava e convexa, intuitivamente"; e, "Sinceramente, eu acho que foi mais de ordem científica, pois a tecnologia ele já sabia [...]", pareceu-nos separar de forma mais contundente o domínio científico do domínio tecnológico, entendendo que a ciência e a tecnologia são domínios independentes sem necessariamente apontar alguma relação entre elas. Acreditamos que tal posicionamento poderá comprometer a articulação dos aspectos CTS nas aulas dessa professora, e transmitir uma visão descontextualizada da ciência e da tecnologia, ao desconsiderar que a ciência e a tecnologia, mesmo sendo domínios independentes, articulam-se mutuamente. Tal discussão apesar de não ter um caráter conclusivo na sua própria formulação, parece contribuir para desmistificar o posicionamento unânime dos professores na entrevista quando consideram a ciência em um estatuto maior do que a tecnologia. As concepções sobre as inter-relações podem ser percebidas com base na tentativa dos professores em responder a questão provocativa sobre a natureza do problema no caso de Galileu.

$\mathrm{Na}$ tentativa de estabelecer uma ordem prioritária na natureza científica ou tecnológica para o problema, a professora A, quando colocou: "Eu acho que de imediato foi cientifico, pois ele não tinha explicação para algumas coisas que ele gostaria. E partindo dai ele precisaria buscar uma nova tecnologia para ampliar a utilização da luneta dele; ele desenvolveu uma tecnologia, mas precisava ser ampliada, ser fundamentada; e eu penso assim. A tecnologia veio de uma necessidade, certo? Só que para você desenvolver uma tecnologia você tem que ter um bom conbecimento científico [...] Ele foi buscar uma fundamentação científica para aprimorar a luneta", parece compreender a ciência como determinante da tecnologia no sentido de ampliar as possibilidades de uso dessa tecnologia. Tal concepção parece emergir da 
Firme, R. N.; Amaral, E. M. R.

supervalorização da ciência frente à tecnologia (VALDÉS et al., 2002). No contexto da sala de aula, para Cachapuz et al. (2005), esse posicionamento docente pode influir negativamente nas propostas CTS de ensino, e comporta, em particular, a falta de compreensão sobre as relações entre a ciência e a tecnologia. Naquele momento, considerando alguns posicionamentos dos professores B e C, respectivamente: "Nem sempre a tecnologia precisa de uma fundamentação teórica por trás" (professor B); "Sinceramente, eu acho que foi mais de ordem cientifica, pois a tecnologia ele já sabia [...]" (professora C), parece-nos que os professores não expressaram explicitamente uma idéia de dependência da tecnologia frente à ciência, e isto poderia ser apontado como uma vantagem para uma perspectiva de ensino CTS. No entanto, não podemos deixar de considerar que as idéias parecem ainda não estar bem estabelecidas para estes professores, o que demandaria maior discussão sobre este ponto. A vantagem estaria no fato de que, não havendo uma idéia de subordinação da tecnologia em relação à ciência, a primeira poderia ser apresentada como aplicação de diversas formas de conhecimentos, e não unicamente como conseqüência do conhecimento científico, para atender as necessidades sociais (SANTOS e SCHNETZLER, 1997). Esta concepção estaria afinada com uma perspectiva CTS para o ensino.

Confrontadas as concepções expressadas nas entrevistas e nos momentos de discussão, consideramos que, para a concepção da inter-relação ciência-tecnologia, a professora A, quando expressou: "Por causa dessa questão da tecnologia consumimos coisas que não nos fazem bem. Para que eu possa fazer uma opsão do que é melhorpara mim, eu preciso do conhecimento científico. A tecnologia pode vir a desenvolver a ciência", reforçou a percepção de que a ciência abre as possibilidades ao desenvolvimento tecnológico. O professor B, por sua vez, expressou um novo posicionamento, pois parece passar a entender que, na relação ciência-tecnologia, a ciência, necessariamente, não precede a tecnologia. A professora C, quando coloca: "A ordem não vai alterar o fato", também apresenta uma idéia diferente sobre a relação ciência e tecnologia: da concepção de que a tecnologia vem unicamente como conseqüência do conhecimento científico, movese em direção ao entendimento no qual ciência e tecnologia são domínios distintos na produção de seus saberes, e que podem se influenciar mutuamente.

Em resumo, consideramos que os novos posicionamentos dos professores sobre ciência, tecnologia, sociedade, e sobre as inter-relações CTS, expressadas nos questionamentos, nas discussões e nas reflexões promovidas nos encontros docentes, representaram um resultado satisfatório e produtivo diante dos objetivos para os quais esses encontros foram propostos. Após as discussões, no encontro seguinte, os professores refletiram sobre os fundamentos teórico-metodológicos de uma abordagem CTS, e, em seguida, passaram ao planejamento das atividades que seriam desenvolvidas em sala de aula. Consideramos que esses encontros foram fundamentais para uma melhor compreensão da proposta de ensino a ser implementada, e que as reflexões feitas, aliadas à experiência vivenciada em sala de aula, deverão contribuir para uma mudança da prática pedagógica desses professores. A análise da implementação da abordagem CTS em sala de aula será objeto de outro artigo. 


\section{Considerações finais}

Com este estudo, verificamos como três professores de química compreendem ciência, tecnologia e sociedade e as inter-relações CTS. A análise dos resultados mostrou que as concepções CTS dos professores foram diversas e houve algumas mudanças de posicionamentos quando foram realizados os encontros de discussão. De forma geral, verificamos convergências em algumas das concepções apresentadas e também identificamos aspectos diferenciados em posições tomadas pelos professores. Além disso, verificamos a existência de concepções que parecem não ser compatíveis com a proposta didática a ser vivenciada por esses professores em sala de aula. Isto aponta para a necessidade de um maior envolvimento dos professores na discussão e elaboração de tal proposta.

Das concepções encontradas com base na análise das entrevistas, emergiram pontos importantes para a discussão, nos encontros com os professores, acerca da ciência, tecnologia e sociedade. Esses pontos foram tratados valendo-se de questionamentos, discussões e reflexões promovidas nos encontros, e apontaram para novos posicionamentos dos professores sobre ciência, tecnologia, sociedade e inter-relações CTS. Dessa forma, podemos considerar que é essencial, em um processo formativo, incluir o tratamento das questões CTS para que os pressupostos teóricos e metodológicos implicados nesta proposta de ensino sejam melhores compreendidos pelos professores envolvidos. Estamos conscientes de que não poderá haver uma expectativa de mudança do professor em curto prazo, mas os momentos de discussão favorecem uma reflexão e sensibilização dos professores, que podem dar suporte ao início de uma mudança que é processual.

De modo geral, as concepções iniciais dos docentes apontam para um quadro no qual a maioria dos professores apresenta a idéia de que o conhecimento científico exerce certa primazia diante de outras dimensões do desenvolvimento humano. Para nós, a repercussão que essas concepções deverão ter em sala de aula, e mais especificamente em uma abordagem CTS, pode ser verificada no tratamento do conhecimento científico com um maior estatuto diante de aspectos tecnológicos e sociais discutidos em sala de aula. $\mathrm{Na}$ sala de aula, de uma forma geral, os professores parecem ter mais facilidade de expressarem idéias relativas aos conceitos científicos que usualmente são apresentados nos livros didáticos, e alguma dificuldade em ampliar a discussão inserindo questões relativas à tecnologia e às questões sociais. Nesse sentido, algumas concepções identificadas neste trabalho poderão se constituir como obstáculos para a implementação de abordagens CTS e outras propostas de contextualização para o ensino. E uma questão se torna relevante: como tratar aspectos tecnológicos e sociais nas aulas de ciências, se idéias sobre as relações entre ciência, tecnologia e sociedade não tiverem um significado expressivo para os professores?

Ao buscar desenvolver estratégias didáticas que representam mudança na sua prática pedagógica, os professores podem se deparar com um processo de reflexão sobre suas concepções e sentir um apelo de revisão das mesmas. Nessa perspectiva, a disponibilidade dos professores em abrir as suas salas de aulas para novas propostas didáticas pode ser compreendida como uma abertura para a sua própria formação. Por essa razão, consideramos que aspectos levantados neste trabalho constituem um ponto de partida importante para a discussão, com esses professores, no processo de elaboração e planejamento de abordagens didáticas a serem aplicadas em suas salas de aula. 
Firme, R. N.; Amaral, E. M. R.

\section{Referências}

ABIB, M. L. V. S. Em busca de uma nova formação de professores. Pesquisas em Ensino de Ciências e Matemática. Bauru: Faculdade de Ciências, Unesp, 1996 (Série Educação para a Ciência, n. 3, p. 60-72).

ACEVEDO, J. Cambiando la práctica docente en la enseñanza de las ciencias a traves de CTS. Borrador, v. 13, n. 13, p. 26-30, 1996 a.

. La formación del profesorado de enseñanza secundaria y la educación CTS. Una cuestión problemática. Revista Interuniversitaria de Formación del Profesorado, v. 26, n. 26, p. 131-144, 1996b.

. Educación tecnológica desde una perspectiva CTS: una breve revisión del tema. Alambique, v. 3, n. 3, p. 75-84, 1995.

AULER, D. Interações entre ciência-tecnologia-sociedade no contexto da formação de professores de ciências. 2002. 218f. (Doutorado em Educação: Ensino de Ciências) Universidade Federal de Santa Catarina, Florianópolis, 2002.

AULER, D.; BAZZO, W. A. Reflexões para a implementação do movimento CTS no contexto educacional brasileiro. Ciência \& Educação, v. 7, n. 1, p. 1-13, 2001.

AULER, D.; DELIZOICOV, D. Ciência-Tecnologia-Sociedade: relações estabelecidas por professores de ciências. Revista electrónica de Enseñanza de las Ciencias, v. 5, n. 2, 2006. Disponível em: <www.saum.uvigo.es/reec/volumenes/volumen5/art8-vol5N2.pdf>. Acesso em: 25 set. 2007.

BAKHTIN, M. Marxismo e filosofia da linguagem. São Paulo: Hucitec, 1992.

CACHAPUZ et al. A necessária renovação do ensino das ciências. São Paulo: Cortez, 2005.

FOUREZ, G. A construção das ciências: introdução à filosofia e à ética das ciências. São Paulo: Editora Unesp, 1995.

FREIRE-MAIA, N. A ciência por dentro. 6. ed. Rio de Janeiro: Vozes, 2000.

KNELLER, G. F. A ciência como atividade humana. Rio de Janeiro/São Paulo: Zahar/ Edusp, 1980.

MARTINS, I. Problemas e perspectivas sobre a integração CTS no sistema educativo português. Revista Electronica de Enseñanza de las Ciencias, v. 1, 2002. Disponível em: <http: www.saum.uvigo.es/reec/volumenes/volumen1/numero1/-art2.pdf > . Acesso em: 26 maio 2006.

SANTOS, W. L.; SCHNETZLER, R. P. Educação química: compromisso com a cidadania. Ijuí: Editora UNIJUÍ, 1997.

SANTOS, W. L. P.; MORTIMER, E. F. Uma análise de pressupostos teóricos da abordagem C-T-S (Ciência-Tecnologia-Sociedade) no contexto da educação brasileira.

Ensaio - Pesquisa em Educação em Ciências, v. 2, n. 2, p. 1-23, 2000. 
SILVA, R. M. G. Ensino de ciências e cidadania. In: SCHNETZLER, R. P.; ARAGÃO, R. M. R. (Orgs.). Ensino de ciências: fundamentos e abordagens. Campinas: R. Vieira Gráfica e Editora, 2000. p. 154-182.

VALDÉS, P. et al. Implicaciones de las relaciones ciencia-tecnologia en la educación científica. Revista Enseñanza de la tecnología, n. 26, 2002. Disponível em: <http:// www.rieoei.org/rie28a04.htm>. Acesso em: 25 jun. 2006.

VANNUCHI A. I. A relação Ciência, Tecnologia e Sociedade no Ensino de Ciências. In: CARVAlHO, A. M. P. (Org.). Ensino de Ciência: unindo pesquisa e a prática. São Paulo: Pioneira Thomson Learning, 2004. p. 77-99. 